\title{
Optimal gastric pouch reconstruction post-gastrectomy
}

\author{
Shayanthan Nanthakumaran ${ }^{1}$, Stuart A. Suttie ${ }^{1}$, Howard W. Chandler ${ }^{2}$, and Kenneth G.M. Park ${ }^{1}$ \\ ${ }^{1}$ Department of Upper Gastrointestinal Surgery, Aberdeen Royal Infirmary, Grampian University Hospital Trust, Aberdeen, AB25 2ZD, \\ UK \\ ${ }^{2}$ School of Engineering and Physical Sciences, University of Aberdeen, Aberdeen, UK
}

\begin{abstract}
Background. Gastric pouches have the potential to improve nutrition following total gastrectomy, compared with standard reconstruction. However, a consensus view of clinical benefit is not available, at least partly due to a lack of standardization of pouch design or size. This study was undertaken to identify optimal conditions for pouch design.

Methods. A mathematical model was established and a porcine model constructed to evaluate the pressure/volume dynamics of the pouch. A " $J$ " pouch was constructed at anastomotic lengths of 5, 10, 15, and $20 \mathrm{~cm}$. Each pouch was distended with saline and the pressure/volume relationship established.

Results. Mathematically, increasing the anastomotic length of the pouch to $15 \mathrm{~cm}$ increases the volume significantly; thereafter, there is minimal benefit of increasing the pouch length further. For smaller pouches $(5$ and $10 \mathrm{~cm})$ a $350-$ to $400-\mathrm{ml}$ volume (approximate meal volume in the elderly) is never achieved until higher pressures $\left(45 \mathrm{cmH}_{2} \mathrm{O}\right)$ are applied. However, in the larger pouches $(15$ and $20 \mathrm{~cm})$ a $350-$ to $400-\mathrm{ml}$ volume is readily achieved at basal pressures of $15 \mathrm{cmH}_{2} \mathrm{O}$.

Conclusion. Smaller pouches never achieve adequate volumes at basal pressures; accordingly, it is unlikely that they will lead to any clinical benefit. Further in-vivo studies should therefore be based upon $15-\mathrm{cm}$ pouch designs.
\end{abstract}

Key words Gastric cancer · Total gastrectomy · Gastric pouch $\cdot$ Reconstruction $\cdot$ Mathematical modeling

\section{Introduction}

Following total gastrectomy, loss of the gastric reservoir and normal duodenal transit results in a group of symp-

Offprint requests to: K.G.M. Park

Received: September 13, 2007 / Accepted: December 19, 2007 toms characterized by symptoms of early satiety, epigastric discomfort, nausea, and vomiting [1]. Reduction in calorie intake due to loss of stomach volume appears to be the single most important determinant of weight loss post-gastrectomy $[2,3]$.

To prevent the consequences of loss of gastric reservoir, over 50 different reconstruction procedures have been reported since the first successful total gastrectomy was described by Schlatter in 1887 [4-6]. Roux, in 1907, described a reconstruction technique, which is currently standard practice at many centers, to establish intestinal continuity following resection of the stomach [4]. However, this does little to improve the reservoir function following surgery. In an attempt to overcome this problem, the first pouch reconstruction was described by Hoffmann in 1922, and was further developed by Hunt in 1952 [7], Rodino in 1952 [8], and Lawrence in 1962 [9]. A combination of the latter three designs, resulting in a "J"-shaped jejunal pouch, has been the most commonly constructed form of gastric pouch. Identifying the optimal reconstruction from the large number of possible techniques continues to be controversial.

A number of studies have suggested that construction of a pouch may improve eating capacity and therefore reduce weight loss following gastrectomy; however, there has been little attempt at standardization of pouch design [10-14]. Furthermore, individual studies of pouch design are generally limited by small patient numbers, short follow-up, and variable outcome measures [10, 15-17]. Due to this variability, a metaanalysis of studies cannot be conducted and, hence, a definitive statement of the benefit of pouch reconstruction cannot be made.

The aims of this study were to construct a mathematical model to quantify gastric pouch volume and justify a range of gastric pouch dimensions to be tested in an in vitro model. 


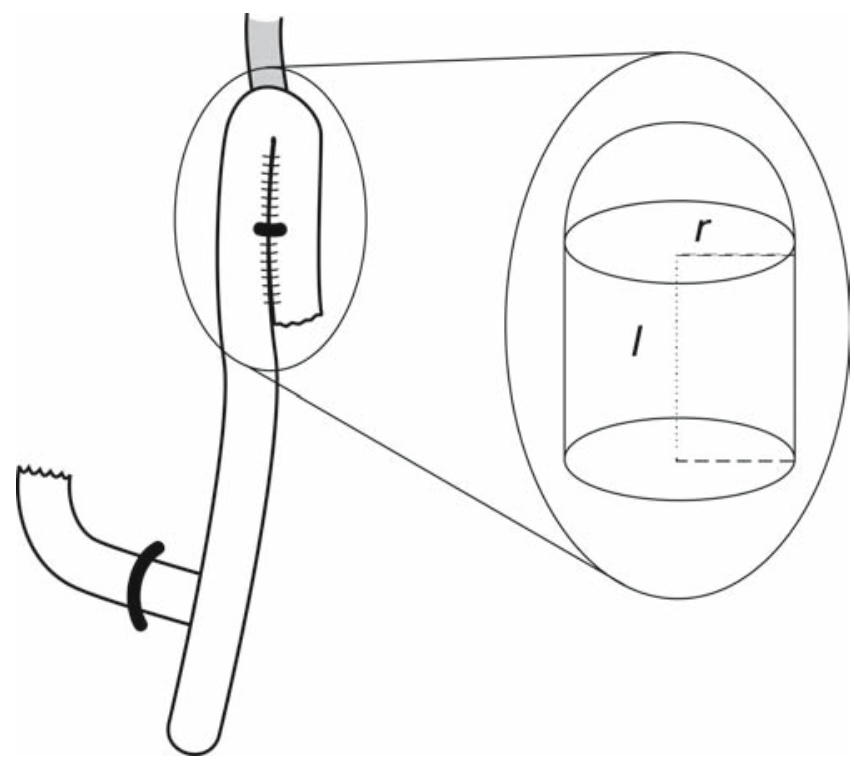

Fig. 1. Mathematical model based on equating the "J" pouch to a hemisphere plus a cylinder. Volume of pouch $=(2 / 3) \pi r^{3}$ $+\pi r^{2} l$, where $r$ is the constant diameter for the jejunum and $l$ is a variable stapled anastomotic length for the pouch

\section{Methods}

\section{Mathematical model}

A mathematical model, based on equating the "J" pouch to a hemisphere plus a cylinder was developed. From this we ascertained a formula to evaluate the volume of a pouch given a constant diameter for the jejunum $(r)$ and a variable stapled anastomotic length (l) for the pouch (Fig. 1). In this way we looked at the increase in pouch volume relative to increasing the stapled length of the anastomosis, and we compared this to the volume of the native length of jejunum required to create the pouch.

The equations used were:

Volume of pouch $=(2 / 3) \pi r^{3}+\pi r^{2} l$

Volume of native length of jejunum $=\pi(r / 2)^{2}(2 l+\pi r)$

\section{In vitro assessment of pouches}

A "J" pouch was constructed, at anastomotic lengths of $5,10,15$, and $20 \mathrm{~cm}$, with porcine intestine, using Ethicon Proximate linear cutters (TLC 55 and TCT 75; EthiconEndo-Surgery, Edinburgh, UK) for the pouch reconstruction and a Proximate curved intraluminal stapler $(29 \mathrm{~mm})$ for the esophagojejunal anastomosis.

Using a specially designed platform (Fig. 2), the pouches were submerged in water (density $1000 \mathrm{~kg} / \mathrm{m}^{3}$ ) prior to distension in order to minimize distortion from gravity. The pouches were suspended from a length of

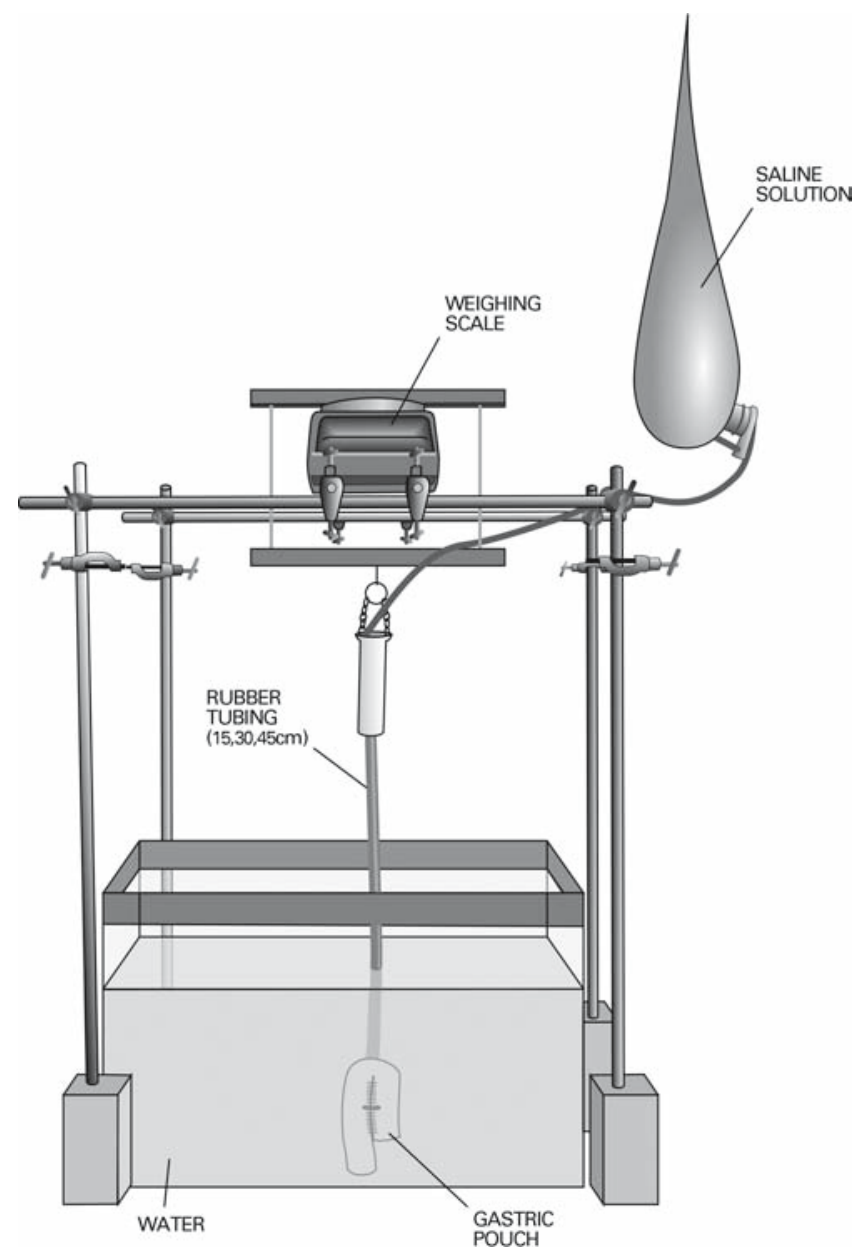

Fig. 2. Platform used for in vitro assessment of constructed pouches

nondistensible rubber tubing attached to a weighing scale.

Three different lengths of rubber tubing were used to generate distending pressures of 15,30 , and $45 \mathrm{cmH}_{2} \mathrm{O}$. The pouches were distended with a continuous flow of $5 \%$ saline solution $\left(50 \mathrm{~g} \mathrm{NaCl}\right.$ in $1000 \mathrm{ml} \mathrm{H}_{2} \mathrm{O}$ - density $1035 \mathrm{~kg} / \mathrm{m}^{3}$ ) to account for potential anastomotic leaks.

The weight change of the nondistended to distended pouch at each pressure was measured and the change in volume calculated using the following formula:

$\Delta V=\Delta W / g\left(\rho_{s}-\rho_{w}\right)$

Where $\Delta V=$ volume change $\left(\mathrm{m}^{3}\right)$

$g=$ acceleration due to gravity $\left(\mathrm{m} / \mathrm{s}^{2}\right)$

$\rho_{s}=$ density of $5 \%$ saline solution $\left(\mathrm{kg} / \mathrm{m}^{3}\right)$

$\rho_{w}=$ density of water $\left(\mathrm{kg} / \mathrm{m}^{3}\right)$

$\Delta W=$ change in measured weight $(\mathrm{N})$

Pouches were constructed in duplicate and measurements performed in triplicate. 


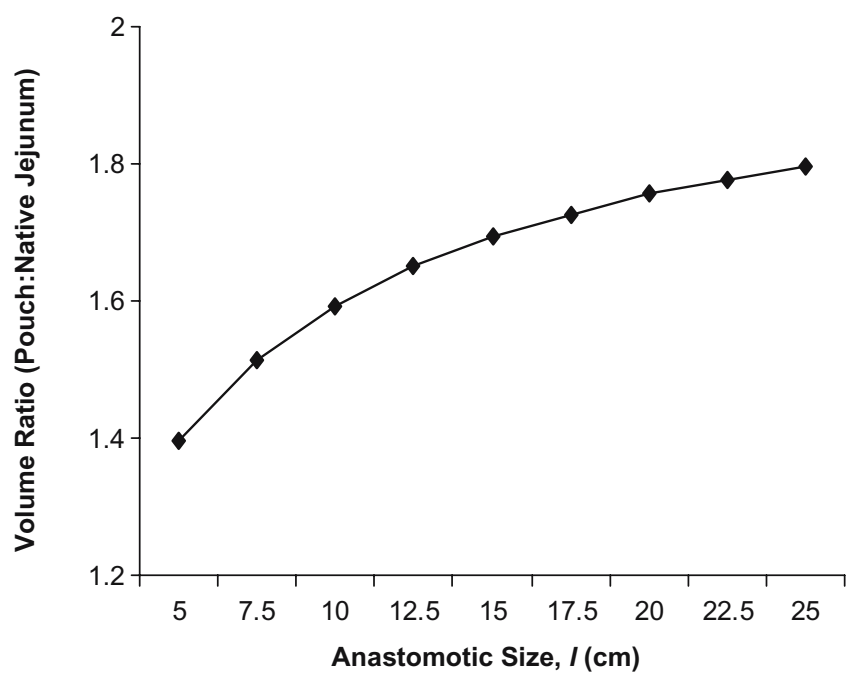

Fig. 3. Mathematically generated pouch volume ratio, pouch: native jejunum

\section{Results}

\section{Mathematical model}

When the diameter of the jejunum remains constant at $3.5 \mathrm{~cm}$ (average diameter of human jejunum), with increasing anastomotic length there is a linear increase in pouch volume. When comparing the volume of the "J" pouch to that of the native length of the jejunum required to create the pouch (volume ratio, pouch: native jejunum), an increase in volume is achieved with a pouch compared to the native jejunum (Fig. 3). This ratio increases with increasing anastomotic length, but begins to plateau at $15 \mathrm{~cm}$, where the volume ratio between pouch and native jejunum is 1.70 (volume of pouch $=668 \mathrm{~cm}^{3}$; volume of native jejunum $=394 \mathrm{~cm}^{3}$ ).

Based on the mathematical model, the following in vitro pouch anastomotic lengths were chosen for further evaluation: $5,10,15$, and $20 \mathrm{~cm}$.

\section{In vitro assessment of pouches}

The 5-, 10-, and 15-cm pouches demonstrated a small increase in volume when distending pressures were increased from 15 to $30 \mathrm{cmH}_{2} \mathrm{O}$. However, when these pressures were increased further from 30 to $45 \mathrm{cmH}_{2} \mathrm{O}$ a proportionally greater increase in volume was noted, in comparison to the initial pressure increase from 15 to $30 \mathrm{cmH}_{2} \mathrm{O}$. A direct correlation between pressure and volume increase was noted with the $20-\mathrm{cm}$ pouches (Fig. 4).

At $15 \mathrm{cmH}_{2} \mathrm{O}$ (basal pressure), volumes of 110,232 , 336 , and $380 \mathrm{ml}$ are achieved with 5-, 10-, 15-, and 20-cm pouch sizes, respectively.

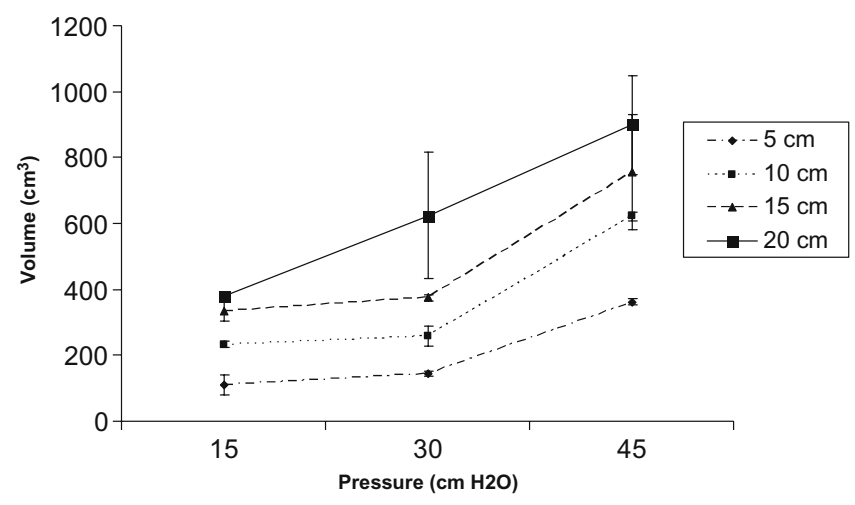

Fig. 4. Pressure/volume analysis for constructed pouches (5, 10,15 , and $20 \mathrm{~cm}$ ). Pouches were constructed in duplicate and measurements performed in triplicate. Data values are presented as means $\pm \mathrm{SD}$

At $30 \mathrm{cmH}_{2} \mathrm{O}$ (intermediate pressure), volumes of $144,258,374$, and $624 \mathrm{ml}$ are achieved with 5-, 10-, 15-, and $20-\mathrm{cm}$ pouch sizes, respectively.

At $45 \mathrm{cmH}_{2} \mathrm{O}$ (high distending pressure), volumes of $361,621,775$, and $898 \mathrm{ml}$ are achieved with 5-, 10-, 15-, and $20-\mathrm{cm}$ pouch sizes, respectively.

\section{Discussion}

\section{Mathematical model}

Our mathematical model highlights the increase in volume that can be obtained when using a length of bowel similar in size, but refashioning it into a "J" pouch.

We have shown that increasing the anastomotic length of the pouch up to $15 \mathrm{~cm}$ increases the volume significantly; thereafter, the same benefit of increasing length does not accrue. This is demonstrated by the plateau seen on the volume ratio, pouch: native jejunum graph (Fig. 3).

Hence, there appears to be reduced mathematical benefit from increasing the anastomotic length beyond $15 \mathrm{~cm}$.

We accept the limitations associated with this simplified mathematical model. In patients, "J" pouches may not always equate to a hemisphere plus a cylinder. However, we felt that this was the most applicable geometric model to use to generate a formula for pouch volumes.

\section{In vitro assessment of pouches}

Liedman et al. [18] demonstrated that intragastric/pouch pressures approaching $15 \mathrm{cmH}_{2} \mathrm{O}$ were tolerated by patients without experiencing symptoms of satiety; 
whereas higher pressures approaching $45 \mathrm{cmH}_{2} \mathrm{O}$ were poorly tolerated by patients, resulting in epigastric pain, nausea, and vomiting.

An average meal size in elderly patients equates to $350-400 \mathrm{ml}$, according to data gathered from our unit. The smaller pouches $(5$ and $10 \mathrm{~cm})$ were unable to achieve such volumes at basal and intermediate pressures, i.e., pressures that would be tolerated by patients without experiencing satiety. With the smaller pouches, in excess of $350 \mathrm{ml}$ was only attainable with distending pressures of $45 \mathrm{cmH}_{2} \mathrm{O}$, at which stage patients would experience troublesome symptoms such as epigastric pain, nausea, and vomiting, in accordance with work carried out by Liedman et al. [18]. However, the larger pouches $(15$ and $20 \mathrm{~cm})$ achieved the desired volume at basal and intermediate pressures which could be tolerated by patients without adverse side effects.

We accept the limitations associated with the use of nonviable bowel within our in vitro assessment and its potentially differing distensible properties when compared to vascularized and innervated human jejunum. We did, however, use freshly harvested porcine intestine during our pouch construction and testing.

Based on our study, there appears to be little benefit of smaller pouches $(5$ and $10 \mathrm{~cm})$ in further in vivo reconstructions, as they are unable to achieve ideal meal volumes at pressures that do not evoke troublesome symptoms in patients. Further in vivo testing should involve larger pouches, i.e., greater than $10 \mathrm{~cm}$, taking into consideration the reduced mathematical benefit gained from exceeding an anastomotic length of $15 \mathrm{~cm}$. Hence, the $15-\mathrm{cm}$ pouches achieve the appropriate pressure/volume dynamics and can be constructed using two $7.5-\mathrm{mm}$ staples.

Acknowledgments We would like to thank Mrs. Michelle MacSorley, ETHICON Endo-Surgery, UK, for supplying the staplers used for constructing the pouches, and Mr. Jim Gall, Materials Laboratory, School of Engineering and Physical Sciences, University of Aberdeen, UK, for helping construct our platform used for assessing the pouches.

\section{References}

1. Olbe L, Lundell L. Intestinal function after total gastrectomy and possible consequences of gastric replacement. World J Surg 1987;11:713-9.
2. Braga M, Zuliani W, Foppa L, Di Carlo V, Cristallo M. Food intake and nutritional status after total gastrectomy: results of a nutritional follow-up. Br J Surg 1988;75:477-80.

3. Bradley EL 3rd, Isaacs J, Hersh T, Davidson ED, Millikan W. Nutritional consequences of total gastrectomy. Ann Surg 1975; $182: 415-29$.

4. Schwarz A, Beger HG. Gastric substitute after total gastrectomyclinical relevance for reconstruction techniques. Langenbecks Arch Surg 1998;383:485-91.

5. Poth EJ, Smith LB. Gastric pouches: their evaluation. Am J Surg 1966;112:721-7.

6. Herfarth C, Schlag P, Buhl K. Surgical procedures for gastric substitution. World J Surg 1987;11:689-98.

7. Hunt CJ. Construction of food pouch from segment of jejunum as substitute for stomach in total gastrectomy. AMA Arch Surg 1952;64:601-8.

8. Rodino D. Technic of esophagojejunal anastomosis following total gastrectomy. J Chir (Paris) 1952;68:716-29.

9. Lawrence W Jr. Reservoir construction after total gastrectomy: an instructive case. Ann Surg 1962;155:191-8.

10. Lehnert T, Buhl K. Techniques of reconstruction after total gastrectomy for cancer. Br J Surg 2004;91:528-39.

11. Kono K, Iizuka H, Sekikawa T, Sugai H, Takahashi A, Fujii H, et al. Improved quality of life with jejunal pouch reconstruction after total gastrectomy. Am J Surg 2003;185:150-4.

12. Iivonen MK, Mattila JJ, Nordback IH, Matikainen MJ. Longterm follow-up of patients with jejunal pouch reconstruction after total gastrectomy. A randomized prospective study. Scand J Gastroenterol 2000;35:679-85.

13. Svedlund J, Sullivan M, Liedman B, Lundell L. Long term consequences of gastrectomy for patient's quality of life: the impact of reconstructive techniques. Am J Gastroenterol 1999;94: $438-45$.

14. Nakane Y, Okumura S, Akehira K, Okamura S, Boku T, Okusa $\mathrm{T}$, et al. Jejunal pouch reconstruction after total gastrectomy for cancer. A randomized controlled trial. Ann Surg 1995;222: $27-35$.

15. Gioffre' Florio MA, Bartolotta M, Miceli JC, Giacobbe G, Saitta FP, Paparo MT, et al. Simple versus double jejunal pouch for reconstruction after total gastrectomy. Am J Surg 2000;180: 24-8.

16. Hoksch B, Ablassmaier B, Zieren J, Muller JM. Quality of life after gastrectomy: Longmire's reconstruction alone compared with additional pouch reconstruction. World J Surg 2002;26: $335-41$.

17. Horvath OP, Kalmar K, Cseke L, Poto L, Zambo K. Nutritional and life-quality consequences of aboral pouch construction after total gastrectomy: a randomized, controlled study. Eur J Surg Oncol 2001;27:558-63.

18. Liedman B, Andersson H, Berglund B, Bosaeus I, Hugosson I, Olbe L, et al. Food intake after gastrectomy for gastric carcinoma: the role of a gastric reservoir. Br J Surg 1996;83:1138-43. 